\title{
OPTIMAL MEASUREMENT OF ICE-SHEET DEFORMATION FROM SURFACE-MARKER ARRAYS
}

\author{
By D. R. MAcAyeaL
}

(Department of Geophysical Sciences, University of Chicago, Chicago, Illinois 60637, U.S.A.)

\begin{abstract}
Aвstract. Surface strain-rate is best observed by fitting a strain-rate ellipsoid to the measured movement of a stake network, or other collection of surface features, using a least-squares procedure. Error of the resulting fit varies as $(\mathrm{L} \Delta \mathrm{t} \sqrt{\mathrm{n}})^{-1}$ where $\mathrm{L}$ is the stake separation, $\Delta \mathrm{t}$ is the time period between initial and final stake survey, and $\mathrm{n}$ is the number of stakes in the network. This relation suggests that, if $\mathrm{n}$ is sufficiently high, the traditional practice of re-visiting stake-network sites on successive field seasons may be replaced by a less costly single-year operation. A demonstration using Ross Ice Shelf data shows that reasonably accurate measurements can be obtained from 12 stakes after only four days of deformation. The least-squares procedure may also aid airborne photogrammetric surveys in that reducing the time interval between survey and re-survey could permit better surfacefeature recognition.
\end{abstract}

Résumé. Mesures de déformation d'une nappe de glace à l'aide d'un réseau de témoins de surface. La vitesse de déformation de surface est très bien obtenue en adaptant un ellipsoïde de déformation au mouvement mesuré d'un réseau de balises ou à d'autres ensembles de marqueurs de la surface avec l'aide d'une optimisation par les moindres carrés. L'erreur résultant de l'approximation varie comme $(\mathrm{L} / \mathrm{t} \sqrt{\mathrm{n}})^{-1}$, ou L est la distance entre balises, $\Delta \mathrm{t}$ la période de temps entre les relevés et $\mathrm{n}$ le nombre de témoins du dispositif. Cette relation suggère qu'avec un n suffisamment élevé, les habituelles visites annuelles peuvent être remplacées par une seule annéc d'operation, bien moins coûteuse. Un test sur les données du Ross Ice Shelf montre qu'une précision raisonnable peut être atteinte avec 12 témoins seulement en 4 jours de déformation. Les moindres carrés peuvent aussi être une aide pour les relevés photogrammétriques aériens, en ce sens qu'en raccourcissant le temps entre deux relevés, ils permettent une meilleure reconnaissance des caractéristiques de la surface.

Zusammenfassung. Optimale Messung der Deformation von Eisdecken mit einem Netz von Oberflächenpegeln. Die Oberflächendeformation wird am besten durch die Anpassung eines Deformationsellipsoides an die in einem Pegelnetz gemessenen Bewegungen oder durch anderweitige Erhebung von Oberflächendaten unter Anwendung der Methode der kleinsten Quadrate bestimmt. Der Fehler der so gewonnenen Anpassung ändert sich mit $(\mathrm{L} \Delta \mathrm{t} \sqrt{\mathrm{n}})^{-1}$, wobei $\mathrm{L}$ der Abstand zwischen den Pegeln, $\Delta \mathrm{t}$ die Zeit zwischen der Anfangs- und Endmessung und n die Anzahl der Pegel im Netzwerk ist. Diese Beziehung lässt vermuten, dass bei genügend grossem n die traditionelle Wiederholungsmessung eines Netzwerkes in aufeinanderfolgenden Feldkampagnen durch eine weniger teure Operation in einem Jahr ersetzt werden kann. Ein Versuch mit Daten vom Ross Ice Shelf zeigt, dass ausreichend genaue Messungen mit 12 Pegeln nach nur vier Tagen der Deformation gewonnen werden können. Das Ausgleichungsverfahren dürfte auch luftphotogrammetrische Aufnahmen erleichtern insofern, als eine Verkürzung der Zeit zwischen Erst- und Zweitaufnahme zu einer besseren Identifizeirung von Oberflächenstrukturen führt.

\section{INTRODUCTION}

Horizontal strain-rate, vertical vorticity, and horizontal velocity observed at the surface of large ice sheets and ice shelves constitute field data essential to the study of large-scale ice-flow dynam$i c s$ and mass balance. These data are traditionally acquired by implanting stake networks and surveying their deformation over a known time interval (Nye, 1959; Zumberge and others, 1960; Drew and Whillans, 1984; Thomas and others, in press). In practice, a one-year time interval is required to allow relative stake displacements in excess of measurement resolution. This one-year period necessitates the deployment of survey parties on two successive field seasons. This paper presents a technique, based on prior work by Nye $(1957,1959)$, that reduces the time interval between initial and final survey and eliminates costly re-deployment of the survey party.

Typical stake networks used to measure the general flow of the Ross Ice Shelf and its grounded margins, for example, consist of four individual stakes arranged in either a rosette or a rectangular pattern (Thomas and others, in press). These networks provide a degree of data redundancy because only three stakes are required to measure horizontal strain-rates and the vertical component of vorticity. In practice, no significance is assigned to apparent deformation gradients within the network, so this redundancy is generally treated by averaging the results of the four triangular sub-arrays (Thomas and others, in press). This study examines the consequence of expanded data redundancy within compact stake networks to determine whether the time interval between survey and re-survey can be shortened to less than one field season. Figure 1 shows an example of such a stake network. The results demonstrate that greater redundancy can shorten field operations and suppress aliasing errors that may occur when small-scale strain-rate
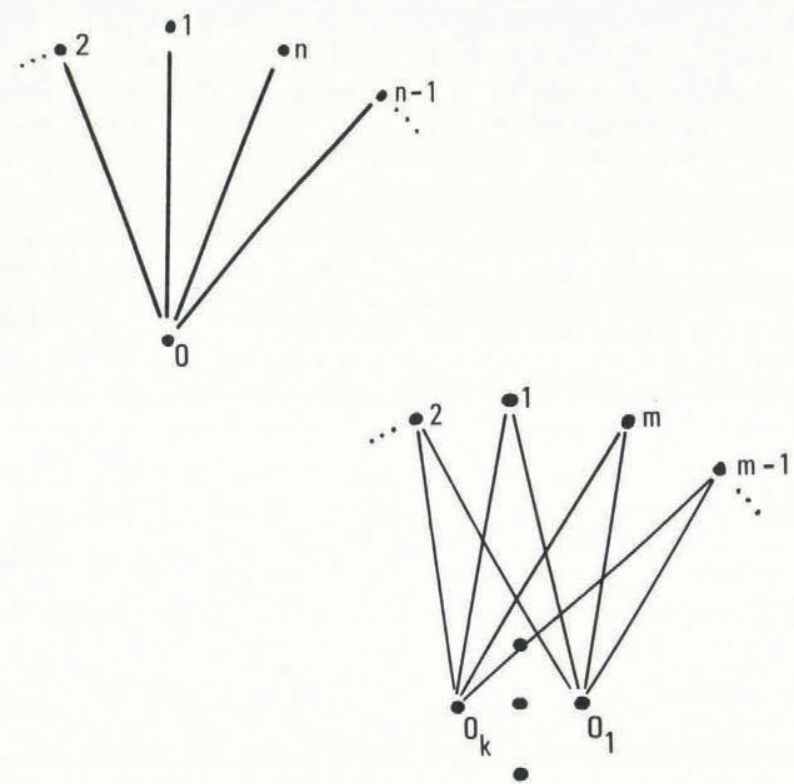

Fig. 1. The idealized n-leg rosette considered in this study for the purpose of error analysis consists of $n$ outlying stakes surrounding a central stake $(0)$ at equal angular intervals and with equal radial separation. Typical rosettes used on the Ross Ice Shelf had $n=3$ (Thomas and others, in press). Also shown above is a modified $n$-leg rosette that uses $m+k<n$ stakes. This rosette design achieves $n$-legs by having $k=n / m$ stakes, and may be more practical under actual field conditions. 
fluctuations are superimposed on the average largescale deformation. The stake-network design features that achieve these advantages may additionally be useful for certain remote-sensing programs that employ large numbers of natural surface features which can become obscured from one year to the next.

\section{SOURCES OF MEASUREMENT ERROR}

The horizontal strain-rate tensor components $\dot{\varepsilon}_{j}$ $(i=1,2 ; j=1,2)$ and vertical vorticity component $\dot{\omega}_{z}$ are defined by the following expressions:

$$
\begin{aligned}
& \dot{\varepsilon}_{i j}=\frac{1}{2}\left[\frac{\partial u_{i}}{\partial x_{j}}+\frac{\partial u_{j}}{\partial x_{i}}\right] \quad i, j=1,2, \\
& \dot{w}_{z}=\left[\frac{\partial u_{2}}{\partial x_{1}}-\frac{\partial u_{1}}{\partial x_{2}}\right]
\end{aligned}
$$

where $\underline{u}=\left(u_{1}, u_{2}, u_{3}\right)$ is the ice velocity and subscripts 1,2 , and 3 refer to a orthogonal coordinate system $(x, y, z)$ having unit vectors $\hat{e}_{x}, \hat{e}_{y}$ and $\hat{e}_{z}$ such that $\hat{e}_{z}$ is perpendicular to the geoid and $\hat{e}_{x}$ and $\hat{e}_{y}$ define the horizontal plane.

Measurement of stake displacements by conventional surveying equipment establishes the velocity gradients required to solve Equations (1) and (2) for $\dot{\varepsilon}_{i j}$ and $\dot{\omega}_{z}$. Sufficient time must be allowed between initial and final survey so that the displacements will exceed measurement error and any unnatural stake disturbances caused by wind or sunlight. If, for example, $\Delta L \approx 0.02 \mathrm{~m}$ is the stake position uncertainty, $L \approx 1.5 \times 10^{3} \mathrm{~m}$ is the stake separation and $\varepsilon=$ $1 \times 10^{-10} \mathrm{~s}^{-1}$ is the strain-rate scale (typical for Ross Ice Shelf conditions), then a time interval of

$$
\Delta t=\frac{100 \mathrm{~L}}{\mathrm{~L} \varepsilon} \approx 0.4 \text { years }
$$

is required between initial and final stake survey to achieve a displacement measurement accuracy of $1 \%$. This time span is generally too long to be fit within a single field season; thus a second field season, incurring the duplicate cost of field-party re-deployment, is required.

An alternative to allowing one year between survey and re-survey is to plant more stakes in each network. From elementary statistics, the measurement error should reduce roughly as $1 / \sqrt{n}$ where $n$ is the number of stakes (or where $n$ is the number of independent measurements of a single stake) (Mendenhall and Scheaffer, 1974). It is thus conceivable that, by choosing $n$ sufficiently high, $\Delta t$ can be reduced to several days or weeks.

A second potential advantage gained by using stake arrays with large numbers of stakes is the reduction of aliasing errors caused by small-scale strain-rate and vorticity fluctuations superimposed on the largescale deformation. Defining $\dot{\varepsilon}_{i j}{ }^{\text {a }}$ as the strainrate averaged over a suitably chosen large-scale distance and $\varepsilon_{j j}$ as the fluctuation around this average, the total strain-rate $\dot{\varepsilon}_{i j}$ may be defined as

$$
\dot{\varepsilon}_{i j}=\dot{\varepsilon}_{i j}{ }^{a}+\dot{\varepsilon}_{i j}{ }^{v} \text {. }
$$

Uniaxial strain-rate data from the Ross Ice Shelf, shown in Figure 2, demonstrates that $\dot{\varepsilon}_{i j} V_{\text {is not }}$ is necessarily smaller than $\dot{\varepsilon}_{i j}{ }^{\mathrm{a}}$ and can vary over a length scale commensurate with the actual 1-2 km stake separations generally used on ice shelves (Thomas and others, in press).

Many field programs are designed to measure $\dot{\varepsilon}_{i j}{ }^{\text {a }}$ rather than $\dot{\varepsilon}_{j j}$; however, it may not be possible to select a stake placement that will average out the
effects of the unknown $\dot{\varepsilon}_{i j}$. Aliasing errors will

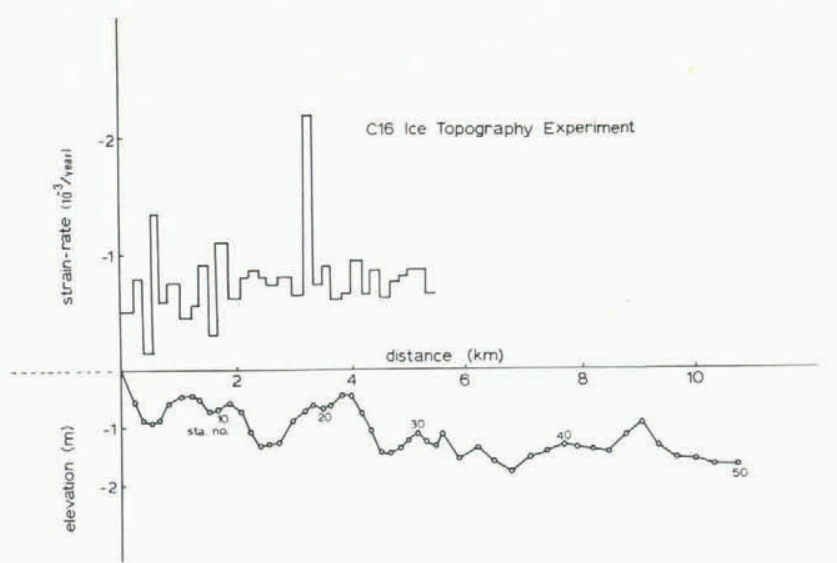

Fig. 2. Uniaxial strain-rate measured on the Ross Ice

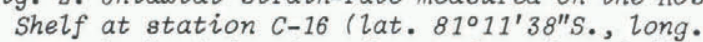
$189^{\circ} 30^{\prime} 09^{\prime \prime} \mathrm{W}$.) is plotted as a function of distance along a line bearing $321^{\circ} \mathrm{T}$. The relative ice-shelf surface elevation along the line is also plotted. open circles denote stake positions. The error level of the observed strain-rate is approximately $1.0 \times 10^{-4} /$ year.

consequently arise in the measured value of $\dot{\varepsilon}_{i j}{ }^{\mathrm{a}}$. The reduction of aliasing errors can be achieved through either increasing the stake separation or increasing the number of stakes to allow, in effect, averaging of individual aliasing errors. Planting stakes with large separations may be ruled out by equipment limitations, so increasing the number of stakes may again provide the best alternative.

\section{STRAIN-RATE ESTIMATION FROM AN OVER-DETERMINED DATA} SET

An $n-1$ eg generalization of the $3-1$ eg rosette stake network used by Thomas and others (in press) on the Ross Ice Shelf will be examined to determine the advantages of redundancy and demonstrate the dataanalysis technique. Each outlying stake of this rosette defines a position vector $\left(x_{i}, y_{j}\right) i=1, \ldots, n$ that will change by $\left(\delta x_{i}, \delta y_{i}\right) i=1, \ldots, n$ as a result of horizontal ice-shelf strain in the time $\Delta t_{i}, i=1, \ldots, n$ between initial survey and resurvey. For purposes of this analysis, (i) the net strain is infinitesimal and (ii) the strain-rate variations over the length scale spanned by the stake network are considered as noise. Rosette design procedures other than those described here should be adopted if either of these conditions is not met.

The set of $n$ observed stake displacements are converted into the four horizontal velocity component gradients $\partial u_{j} / \partial x_{j}, i, j=1,2$ by solving the following linear equation:

$$
\underline{A} \cdot \underline{s}=\underline{d}-\underline{z} \text {. }
$$

Here $\underline{s}$ is the column vector

$$
\left(\frac{\partial u_{x}}{\partial x}, \frac{\partial u_{x}}{\partial y}, \frac{\partial u_{y}}{\partial x}, \frac{\partial u_{y}}{\partial y}\right)^{\top}
$$

representing the true local average of the horizontal velocity gradients, $\underline{d}$ is the column vector

$$
\left(\frac{\delta x_{1}}{\Delta t_{1}} \frac{\delta x_{2}}{\Delta t_{2}}, \ldots, \frac{\delta x_{n}}{\Delta t_{n}}, \frac{\delta y_{1}}{\Delta t_{1}}, \frac{\delta y_{2}}{\Delta t_{2}}, \ldots, \frac{\delta y_{n}}{\Delta t_{n}}\right)^{\top}
$$

that represents the measured stake displacements resulting from the true ice strain $\underline{s}, \underline{z}$ is the column vector 


$$
\left(\frac{\sigma_{1}}{\Delta t_{1}}, \frac{\sigma_{2}}{\Delta t_{2}}, \ldots, \frac{\sigma_{n}}{\Delta t_{n}}, \frac{\sigma_{n+1}}{\Delta t_{1}}, \frac{\sigma_{n+2}}{\Delta t_{2}}, \ldots, \frac{\sigma_{2 n}}{\Delta t_{n}}\right)^{\top}
$$

that represents the disturbance of the true stake displacements resulting from inaccurate measurement and from actual strain-rate variation over the rosette, and $A$ is the $2 n \times 4$ stake-position matrix given by

$$
\underline{A}=\left[\begin{array}{cccc}
x_{1} & y_{1} & 0 & 0 \\
\cdot & \cdot & \cdot & \cdot \\
x_{n} & y_{n} & 0 & 0 \\
0 & 0 & x_{1} & y_{1} \\
\cdot & \cdot & \cdot & \cdot \\
0 & 0 & x_{n} & y_{n}
\end{array}\right] .
$$

The noise vector $z$ is assumed to be a random variable characterized by the following $2 \mathrm{n} \times 2 \mathrm{n}$ covarience matrix $\left\langle\underline{z} \underline{z}^{\top}>\right.$ :

$\left\langle\underline{z} \underline{z}^{T}\right\rangle=\left[\begin{array}{cc}\frac{\sigma_{1}{ }^{2}}{\Delta t_{1}{ }^{2}} & \\ \frac{\sigma_{n}{ }^{2}}{\Delta t_{n}{ }^{2}} & 0 \\ \frac{\sigma_{n+1}{ }^{2}}{\Delta t_{1}{ }^{2}} & \\ 0 & \frac{\sigma_{2 n^{2}}}{\Delta t_{n}{ }^{2}}\end{array}\right]$.

In the above representation of $\left\langle z z^{T}\right\rangle$, the error in measuring one stake is assumed, for simplicity, to be uncorrelated with those of other stakes. The uncertainty of one stake's displacement, however, may be greater than another's. In more complex situations, errors in measuring different stakes may be correlated. In this circumstance, the data pre-weighting matrix W defined in the following section should be chosen $\overline{\bar{t}} Q$ diagonalize $\left\langle\underline{z} \underline{z} \underline{z}^{\top}\right\rangle$.

The matrix A contains all the information regarding the number and positioning of the rosette stakes. In general, A will have a greater number of rows than columns becaūse it maps a given element $s$ of the "velocity-gradient vector space" having a dimensionality of 4 into an element d of the "data vector space" having a dimensionality equal to twice the number of stakes. Note, however, that not all possible elements of the data space are accessible through $A$ from an element of the velocity-gradient space. Thēse inaccessible data elements constitute the measurement of noise and provide no information useful for calculating s. The objective of the data-analysis technique presented here is to select an inverse of A that discards all inaccessible data elements.

\section{PRE-WEIGHTING AND SCALING}

Before deriving the inverse of A, Equation (5) is modified so that the covariance mat $\bar{T} i x\langle z z\rangle$ has equa diagonal elements and the variables are scaled dimensionless quantities of order one (Wunsch, 1978). The dimensionless weighting matrix $\underset{W}{=}$ defined by

$$
W_{i j}=\frac{\sigma^{2} \Delta t_{i}^{2}}{\sigma_{i}^{2}} \delta_{i j} ; \quad i, j=1, \ldots, 2 n
$$

where

$$
\begin{aligned}
& \sigma^{2}=\frac{1}{2 n} \sum_{i=1}^{2 n} \sigma_{i}{ }^{2} / \Delta t_{i}{ }^{2}, \\
& \delta_{i j}=0 \text { if } i \neq j, \text { and }
\end{aligned}
$$

$\delta_{\text {to }} j=1$ if $i=j$, is used to transform Equation

$$
\underline{\underline{W}}^{1 / 2} \cdot \underline{A} \cdot \underline{\underline{s}}=\underline{\underline{W}}^{1 / 2} \cdot \underline{\mathrm{d}}-\underline{\underline{W}}^{1 / 2} \cdot \underline{z}
$$

where $W^{1 / 2} i j=\sqrt{W_{i j}}$. Observe that now $\left\langle W^{1 / 2} \cdot z z^{\top} \cdot W^{/ 2}{ }^{\top}\right\rangle=\sigma^{2}$ I. To avoid unnecessary notational comp Tication, however, the factors $W^{1 / 2}$ will be henceforth dropped from Equation (9)

The purpose of the weighting matrix $\mathrm{w}^{1 / 2}$ is to render each component of each observed stake displacement rate in a form having the same uncertainty. In practice, the displacement rate vectors $\left(\delta x_{j} / \Delta t\right.$, $\left.\delta y_{j} / \Delta t_{j}\right) i=1, \ldots, n$ are measured in polar coordinate $\left(\delta R_{j} / \Delta t_{j}, \delta \theta_{j} / \Delta t_{j}\right) i=1, \ldots, n$ where the uncertainty of $\delta \theta_{j}$ is considerably higher than $\delta R_{j} / R_{j}$. This disparity results from the practical limitations of conventional theodolite and electronic distance measuring devices. Typically, accuracies of $\pm 0.5 \times 10^{-2} \mathrm{~m}$ and $\pm 10^{\prime \prime}$ are attainable for $\delta R_{j}$ and $\delta \Theta_{i}$, respectively. Unless the outlying stakes are placed closer than c. $100 \mathrm{~m}$ from the central stake, these disparate measurement uncertainties will render the uncertainty of the tangential component of $\left(\delta x_{i}, \delta y_{i}\right)$ greater than that of the radial component.

The advantage of using the weighting matrix $w^{1 / 2}$ is that it allows the data elements of $d$ representing radial displacements to weigh more heavily than those representing tangential displacements.

Non-dimensionalization of variables is accomplished by defining the length and strain-rate scales $L, \dot{\varepsilon}=\left[{ }_{2}^{1} \dot{\varepsilon}_{i j} \varepsilon_{i j}\right]^{1 / 2}$, and by transforming the variables as follows:

$$
\begin{aligned}
& A_{i j} \longrightarrow(L) A_{i j}, \\
& \frac{\partial u_{j}}{\partial x_{j}} \longrightarrow \frac{\partial u_{j}}{\partial x_{j}} \\
&\left(\frac{\delta x_{\ell}}{\Delta t_{\ell}}, \frac{\delta y_{\ell}}{\Delta t_{\ell}}\right) \rightarrow\left(\frac{\dot{\varepsilon} L}{\Delta t}\right)\left(\delta x_{\ell}, \delta y_{\ell}\right),
\end{aligned}
$$

and

$$
z_{\ell} \longrightarrow \sigma z_{\ell}
$$

where $A_{i j}, \partial u_{j} / \partial x_{j}, \delta x_{\ell}, \delta y_{\ell}$, and $z_{\ell}$ are now of order on Equation (9) may be expressed in terms of the nondimensional uncertainty parameter $(\sigma / \varepsilon \mathcal{E} L t)$ :

$$
\underline{\underline{A}} \cdot \underline{\underline{s}}=\underline{d}-(\sigma / \varepsilon \dot{\varepsilon} L \mathrm{t}) \underline{z},
$$

Scaling Equation (9) in this way will simplify the forthcoming discussion on how to best select $\Delta t$ and $L$ from prior estimates of $\varepsilon$ and $\sigma$.

\section{SINGULAR-VALUE DECOMPOSITION}

The estimate $\underline{S}_{e}$ that minimizes the error $\left\|\underline{A} \cdot \underline{S}_{e}-d\right\|$ defined by 


$$
\|\underline{A} \cdot \underline{S} \underline{e}-\underline{d}\|=\left[\sum_{i=1}^{2 n}\left(\sum_{\ell=1}^{4} A_{i \ell} S_{e \ell}-d_{i}\right)^{2}\right]^{1 / 2} .
$$

is obtained by the singular-value decomposition method (Lawson and Hanson, 1974; Wunch, 1978). According to this method, A is decomposed into the product of three associated matrices that are more readily invertable:

$$
\stackrel{A}{=} \underline{\underline{Q}} \cdot \stackrel{r}{=} \cdot \underline{R}^{\top} \text {. }
$$

The $4 \times 4$ matrix $I$ is diagonal and is composed of the eigenvalues $\lambda_{i}, i=1, \ldots, 4$ a ssociated with the following linear equations

$$
\stackrel{A}{=}^{\top} \cdot \stackrel{A}{=} \cdot r_{\ell}=\lambda_{\ell}^{2} r_{\ell} \quad \ell=1, \ldots 4,
$$

and

$$
\stackrel{A}{=} \cdot \stackrel{A}{ }^{\top} \cdot q_{\ell}=\left\{\begin{array}{ll}
\lambda_{\ell}{ }^{2} & q_{\ell} \\
0 & \quad
\end{array}\right\} \quad \begin{aligned}
& \ell=1, \ldots, 4 \\
& \ell=5, \ldots, 2 n .
\end{aligned}
$$

The normalized eigenvectors of $\underline{\underline{A}} \cdot \underline{\underline{A}}^{\top}$ and $\underline{\underline{A}} \cdot \cdot \underline{\underline{A}}, q_{\ell}$ and $r_{\ell}$ respectively, comprise the columns of $Q$ and the rows of $\underline{R}^{\dagger}$ respectively. The inverse matrīces $\underline{R}^{T-1}$ and $\underline{Q}^{-1}$ are easily obtained by taking the transposes of $R^{T}$ and $Q$. This simplicity results from the orthonormality $\overline{\bar{m}}$ of the eigenvectors $q_{\ell}$ and $r_{\ell}$.

The inverse of $\stackrel{A}{=}$ is $^{*}$

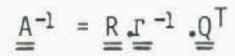

where $\Gamma^{-1}$ is the $4 \times 4$ diagonal matrix composed of diagonal elements $\Gamma_{i j}{ }^{-1}=1 / \lambda_{j}, i=1, \ldots, 4$. Equation (9) is solved by applying $\stackrel{A}{-1}^{-1}$ to the observed data $\underline{\text { d, so that }}$

$$
\underline{S}_{e}=\underline{A}^{-1} \cdot \underline{d}=\underline{R}_{\underline{r}}^{=} \underline{\underline{T}}^{-1} \cdot \underline{\underline{Q}} \cdot \underline{d} \cdot
$$

The expectation value of the error variance,

$\left.<\left(\underline{S}_{e}-\underline{S}\right)\left(\underline{S}_{e}-\underline{S}\right)^{T}\right\rangle_{i j} i=1, \ldots, 4$, is given by

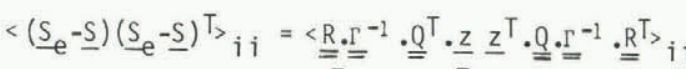

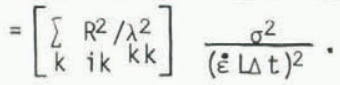

Equation (18) states that the error of each component of Se depends on the eigenvalues of $\underline{I}$ and the eigenvectors $\underline{r}_{i}, i=1, \ldots .4$.

\section{OPTIMAL ROSETTE DESIGN}

The task of designing the best rosette amounts to choosing the adjustable parameters $\Delta t, L$, and $\left(x_{i}, y_{i}\right), i=1, \ldots, n$ that satisfy a design criterion given by Equation (18) restated as

$$
\operatorname{Max}_{i}\left[\sum_{k} R_{i k}^{2} / \lambda_{k}^{2}\right]_{k} \frac{\sigma^{2}}{(\dot{\varepsilon} L t)^{2}}<E \text {, }
$$

where $E$ is the desired accuracy level (expressed in units scaled by $\varepsilon^{2}$ ). Here, $\sigma^{2}$ is a parameter combining information about the surveying equipment and natural strain-rate variation, and $\varepsilon$ is estimated or determined from prior data. In practice, it is best to choose $\mathrm{L}$ as long as possible $(c .2 \mathrm{~km})$; therefore

*The complex algebraic manipulations required to perform singular-value decomposition of A are easily done by computer programs now available on most university computer systems (Dongarra and others, 1979). only $n$ and $\Delta t$ will be considered adjustable in the following discussion.

To derive the design criterion, the $n-1$ eg rosette will be idealized as a system of $n$ outlying stakes placed regularly on a circle at angular intervals of $\Delta \Theta=2 \pi / n$. In practice, however, allowances must be made for deviations from this ideal configuration. Assuming that $\delta R$ and $L \delta \theta$ are the intrinsic radial and tangential uncertainties of observed stake displacements, the non-dimensional and pre-weighted version of the matrix $\stackrel{A}{=}$ is given by:

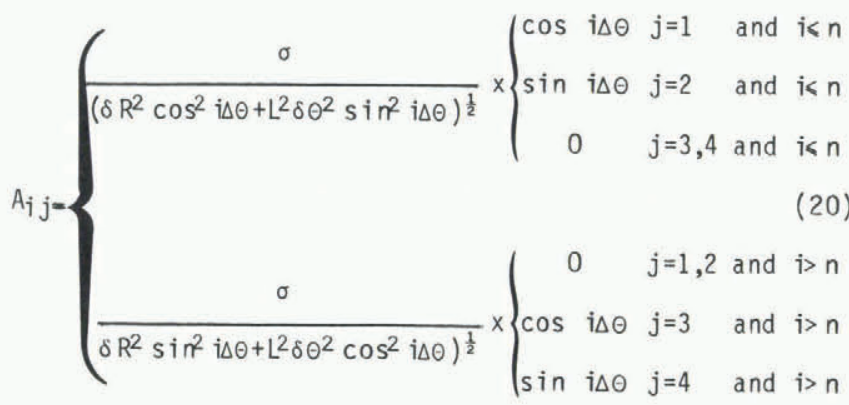
where $\sigma^{2}=\frac{1}{2 n} \sum_{i=1}^{n}\left[\left(\delta R^{2} \cos ^{2} i \Delta \theta+L^{2} \delta \theta^{2} \sin ^{2} i \delta \theta\right)^{\frac{1}{2}}+\right.$ $\left.\left.+\delta R^{2} \sin ^{2} i \Delta \theta+L^{2} \delta \theta^{2} \cos ^{2} i \Delta \theta\right)^{\frac{1}{2}}\right]$.

The value of

$$
\left.\operatorname{Max}_{i} \mathbb{R}_{k} R_{i k} / \lambda_{k}^{2}\right]\left[\sigma^{2} /(\dot{\varepsilon} L t)^{2}\right]
$$

expressed as a percentage of $\dot{\varepsilon}$ is presented as a function of $n$ and $\Delta t$ in Figure 3 for parameter values $\mathrm{L}=2 \mathrm{~km}$ and $\dot{\varepsilon}=10^{-10} \mathrm{~s}^{-1}$. Observe that this error

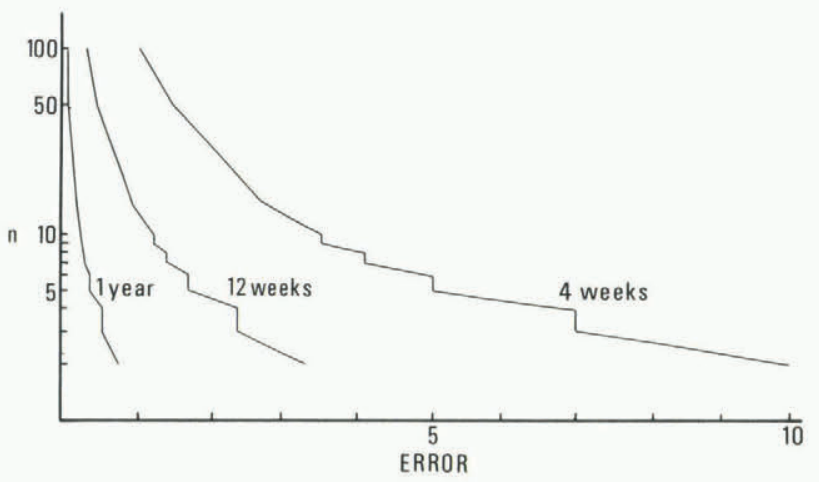

Fig. 3. The maximum error of the velocity gradients, expressed as percent of $\varepsilon$, is plotted as a function of $n$ and $\Delta^{t}$. Scale factors used in the calculation of these graphs are $\dot{\varepsilon}=10^{-10} / \mathrm{s}$ and $L=2.0 \times 10^{3} \mathrm{~m}$. Notice that $3 \%$ accuracy can be achieved by a 13-leg rosette in 28 d or by a 3-leg rosette in $84 d$. Under some circumstances, it may be preferance to deploy rosettes having $n>15$ so that all measurements can be accomplished within one field season. This diagram, and other similar ones, can be used by field glaciologists to design their field program to maximize the data return for a given logistic effort.

value varies as $(\Delta t \sqrt{n})^{-1}$. As shown in Figure 3 , a choice of $n=13$ would yield $3 \%$ accuracy within a time span of four weeks.

\section{DEMONSTRATION}

A stake network planted up-stream of Crary Ice Rise on the Ross Ice Shelf demonstrates the data-analysis 


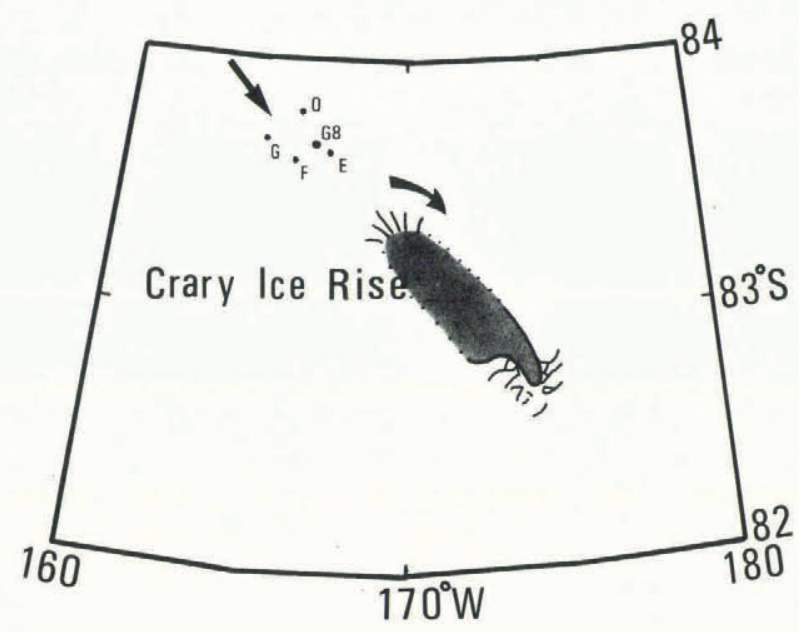

Fig. 4. Four 3-leg rosetts (O, E, F, G) planted upstream of Crary Ice Rise on the Ross Ice Shelf were re-surveyed after an average time period of $4.3 \mathrm{~d}$. A fifth rosette $\left(G_{8}\right)$ planted during RIGGS provides an accurate measurement of the actual strain-rate to be used as a reference. In this study, the four 3 -leg rosettes are combined into one $12-$ leg rosette to see how the subsequent strain-rate measurement provided by the 4.2 d period compares with the actual strain-rate.

procedure associated with the n-leg rosette. Figure 4 shows the disposition of four three-leg rosettes $(0, E, F, G)$ planted in 1983 as part of a field project by Robert Bindschadler and others to measure strainrates up-stream of an ice rise. The position of a much older three-leg rosette planted in 1973 (G8) falls within the area enclosed by the four new rosettes. This older rosette was re-surveyed in 1974 as part of the Ross Ice Shelf Geophysical and Glaciological Survey (RIGGS) (Thomas and others, in press); and yielded an accurate strain-rate determination $( \pm 9 \%)$ with which data from the new rosettes may be compared.

The four rosettes planted in 1983 were each surveyed and re-surveyed within a time interval spanning $4.2 \mathrm{~d}$. This re-survey was conducted primarily to check survey equipment and to scan for possible zones of ultra-high deformation. Here, however, the re-survey data will be used to test the ability of a 12-leg rosette to yield an accurate measurement in a short time interval. The imaginary $12-1$ eg rosette is synthesized from the four smaller rosettes by treating each of their central stakes as one. Actual strainrate gradients expected within the field area will degrade the accuracy of the synthesized 12-leg rosettes because the smaller 3 -leg rosettes are separated from each other by up to $15 \mathrm{~km}$. Nevertheless, the synthesization provides an otherwise unavailable opportunity to demonstrate a $12-1$ eg rosette measurement.

Figure 5 shows the stake disposition for the synthesized $12-\mathrm{leg}$ rosette, and indicates the observed stake velocities relative to the combined central stakes. Except for two stakes corresponding to rosette 0 , tangential displacements were not measured. Angular displacements required to observe the tangential components would have been below the accuracy level ( $\left.\pm 10^{\prime \prime}\right)$ of the theodolites used in this project, so any unknown tangential displacements were arbitrarily assumed to be zero.

The results of the $12-1$ eg rosette analysis are compared with the known strain-rates in Figure 5 and in Table I. The two principal strain-rate components (denoted $\varepsilon_{11}$ and $\varepsilon_{22}$ ) given by the $12-1$ eg rosette

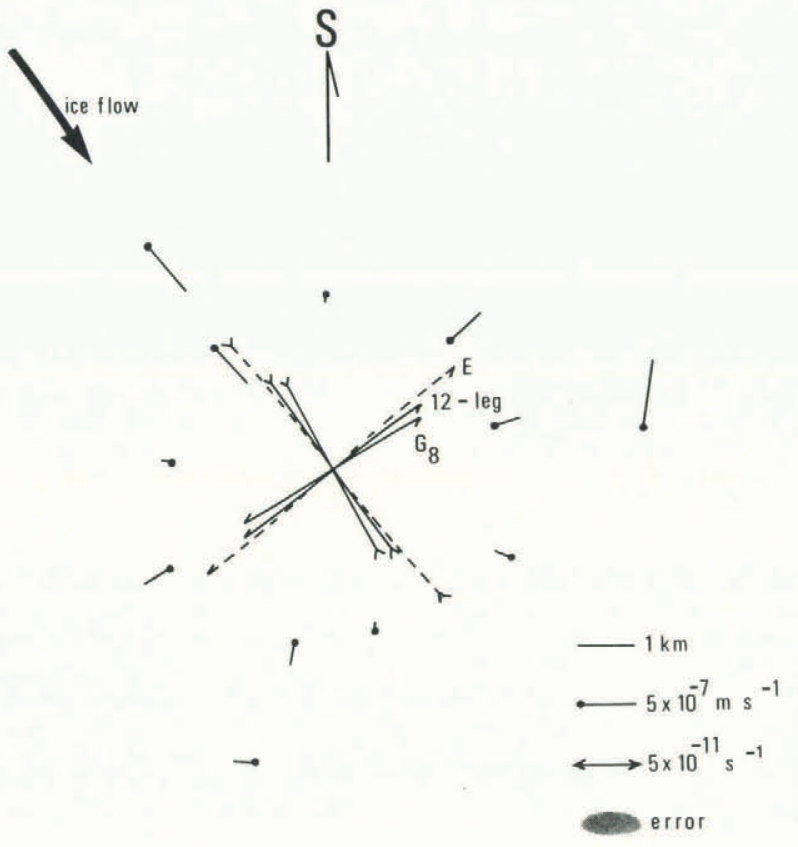

Fig. 5. Stake positions of the 12 -leg rosette are mapped along with the relative stake velocities. The principal axes of the strain-rate measured using the 12-leg rosette are compared with those measured during RIGGS $\left(G_{8}\right)$ (Thomas and others, in press). Also shown are the principal axes resulting from the 3 -leg rosette $E$ using a 3.9 d interval between survey and re-survey. Uncertainty of the observed velocities is variable. The shaded ellipse represents, for example, the velocity uncertainty for the three most outlying stakes. The ellipse should be oriented perpendicular to the position vector.

differ from the known values by $9 \%$ and $14 \%$, respectively; and their orientations are displaced by $6^{\circ}$. The unsatisfactory results produced by the $3-1$ eg rosette (E) closest to $\mathrm{G}_{8}$, using the data analysis procedure out 1 ined by Thomas and others (in press), are also shown in Figure 5 and Table $I$ as a contrast to the results of the $12-1$ eg rosette.

\section{PRACTICAL CONSIDERATIONS}

It would be a mistake to adopt rosettes with large $n$ without first considering the limitations imposed by logistic support, survey technology, and the various benefits of a multi-year field program not emphasized in this study. It is, of course, always desirable to plant rosettes with large $n$. This desire conflicts, however, with the need to minimize the field-party work-load, especially when aircraft support limits the time a field party can spend at each field site. If field programs encompass a large number of field sites, the 3- or 4-leg rosette may be best because field operations would be likely to span several years regardless of whether individual sites were re-visited in the same or in a succeeding field season. For field programs covering a small area, such as that conducted up-stream of the Crary Ice Rise, rosettes with greater numbers of stakes may be preferable so that the entire field project can be accomplished in several weeks.

In view of the need to reduce the field-party workload, several design inodifications to the n-leg rosette may prove useful. Figure 1 shows, for example, how planting $k$ central stakes and m outlying stakes will achieve a high data redundancy while reducing the total number of stakes and the surveying workload. Surveying the $m$ outlying stakes from $k$ independent 
TABLE I. PRINCIPAL STRAIN-RATES $\left[\dot{\varepsilon}_{11}\right.$ and $\dot{\varepsilon}_{22}$ ] MEASURED BY VARIOUS ROSETTES

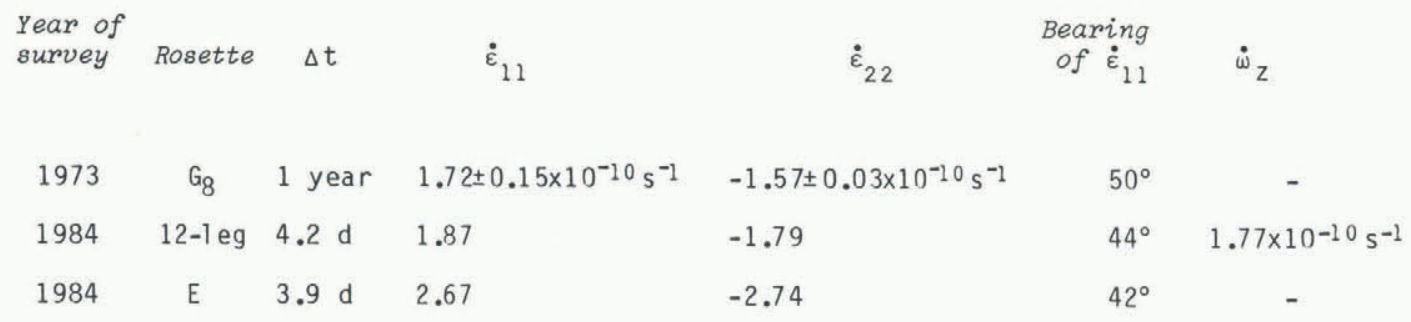

central locations yields $k$. $m=n$ independent measurements of stake displacement. Only $m+k<n$ stakes are required by this non-ideal n-leg rosette; and if appropriate measures are taken (e.g. assigning a separate corner-reflector prism to each outlying stake) the surveying can be accomplished within a reasonable time.

\section{CONCLUSION}

The stake-network designs that best measure surface strain-rates and vorticity encompass a large degree of redundancy. The more stakes included in each network, the less individual stake displacement errors will affect the overall measurement. The advantage gained at the expense of the redundancy is the reduced time interval between survey and re-survey.

Redundancy may also be a key element in the design of future field programs based on remote-sensing techniques such as airborne photogrammetry. Brecher (1982), for example, has used photographs of natural features to identify the motion of the Byrd Glacier. These natural features are available in virtually unlimited number, and so provide, in principle, a natural equivalent of a large-n rosette. A shortened time interval between initial and final aerial photographic missions may reduce the camouflaging of natural features by drifting snow, and may, therefore, ultimately achieve greater accuracy by virtue of higher data redundancy.

\section{ACKNOWLEDGEMENTS}

R.A. Bindschadler, H.J. Zwally, M. Sturm, J. Scofield, and D. Lindstrom helped survey the stake network near Crary Ice Rise. R.H. Thomas, E. Penn, M. Hyland, and M. Jordan helped survey the stake network near C-16. V. Barcilon originally suggested this research topic to me. Ms Glenda York provided typing and editorial assistance. This research was supported by NASA Grant No. NAG 5-394.

\section{REFERENCES}

Brecher, H.H. 1982. Photogrammetric determination of surface velocities and elevations on Byrd Glacier. Antarctic Journal of the United States, Vol. 17, No. 5, p. 79-81.

Dongarra, J.J., and others. 1979. Linpack users' guide, by J.J. Dongarra, C.B. Moler, J.R. Bunch, and G.W. Stewart. Philadelphia, Society for Industrial and Applied Mathematics.

Drew, A.R., and Whillans, I.M. 1984. Measurements of surface deformation on the Greenland ice sheet by satellite tracking. Annals of Glaciology, Vol. 5, p. 51-55.

Lawson, C.L., and Hanson, R.J. 1974. Solving least squares problems. Englewood Cliffs, N.J., Prentice$\mathrm{Ha} 11$.

Mendenha11, W., and Scheaffer, R.L. 1973. Mathematical statistics with applications. North Scituate, Mass., Duxbury Press.

Nye, J.F. 1957. Physical properties of crystals: their representation by tensors and matrices. Oxford, Clarendon Press.

Nye, J.F. 1959. A method of determining the strainrate tensor at the surface of a glacier. Journal of Glaciology, Vol. 3, No. 25, p. 409-19.

Thomas, R.H., and others. In press. Glaciological studies on the Ross Ice Shelf, Antarctica, 19731978, by R.H. Thomas, D.R. MacAyeal, D.H. Eilers, and D.R. Gaylord. (In Hayes, D., and Bentley, C.R., ed. The Ross Ice Shelf: glaciology and geophysics. Washington, D.C., American Geophysical Union. (Antarctic Research Series.)

Whillans, I.M. In press. Ice stream dynamics. Antarctic Journal of the United States.

Wunsch, C. 1978. The North Atlantic general circulation west of $50^{\circ} \mathrm{W}$ determined by inverse methods. Reviews of Geophysics and Space Physics, Vol. 16, No. 4 , p. 583-620.

Zumberge, J.H., and others. 1960. Deformation of the Ross Ice Shelf near the Bay of Whales, Antarctica, by J.H. Zumberge, M. Giovinetto, R. Kehle, and J. Reid. I.G.Y. Glaciological Report Series (New York), No. 3 . 